\title{
In the Classroom
}

\section{Cultural Competence in Alberta Schools: Perceptions of ESL Families in Four Major School Boards}

\section{Hieu V. Ngo}

Complex linguistic, acculturative, and social needs of English-as-a-second-language (ESL) learners challenge the K-12 education system to develop cultural competence in working with culturally diverse families. This study surveyed 242 self-identified ESL students and their parents from four of Alberta's major school boards. Results of the survey questionnaire offer insights into the perception of ESL learners and their parents on how Alberta schools respond to cultural diversity with respect to school environment, cultural representation, school practices, competence of school staff, school-and student-family interactions, family-school communication, school-community collaboration, and involvement of families in school activities.

Les besoins complexes qu'affichent les apprenants en ALS sur le plan linguistique, culturel et social mettent au défi le système d'éducation K-12 pour qu'il développe des compétences culturelles permettant de fonctionner avec des familles offrant des profils culturels diversifiés. Nous avons fait une enquête auprès de 242 élèves s'affichant eux-mêmes comme apprenants en ALS et de leurs parents dans quatre des plus grands conseils scolaires en Alberta. Les résultats du questionnaire exposent les perceptions qu'ont les apprenants en ALS et leurs parents de la réaction des écoles albertaines face à la diversité culturelle en fonction du milieu scolaire; de la représentation culturelle; des pratiques scolaires; de la compétence du personnel de l'école; des interactions entre l'école, les élèves et leurs familles; de la communication entre l'école et les familles; de la collaboration entre l'école et la communauté; et de l'implication des familles dans les activités scolaires.

Growing cultural diversity has transformed communities across Alberta. According to the 2006 Census, the foreign-born and visible-minority populations in Alberta are 16.2\% and 13.9\% respectively (Statistics Canada, 2008). In the K-12 education system, the English-as-a-second language (ESL) student population has grown exponentially. In fact, the number of identified ESL learners has increased from 28,837 in the 2003-2004 school year to 61,499 in the 2010-2011 school year (Alberta Education, 2011). ESL learners are diverse in terms of racial, ethnic, religious, and linguistic backgrounds. Their diver- 
sity provides ample opportunities for meaningful intercultural exchange and learning in schools. At the same time, their complex linguistic, acculturative, and social needs challenge the K-12 education system to develop competence in working with culturally diverse families.

This article examines from the perspective of ESL learners and their parents, how Alberta schools have responded to cultural diversity. It draws on the 2007-2008 survey of 242 self-identified ESL learners and 242 parents of those learners in the four major school boards in Calgary and Edmonton, namely, Calgary Board of Education (CBE), Calgary Catholic School District (CCSD), Edmonton Public School Board (EPSB), and Edmonton Catholic School District (ECSD). Two specific research questions frame the analysis: (a) To what extent from the perspective of ESL families have Alberta schools addressed cultural diversity in the various aspects of organizational structures and functions? and (b) Are there differences in the perceptions of ESL learners and their parents about schools' responses to cultural diversity?

\section{Background}

Learners with an ESL background often face unique linguistic, educational, and social challenges. Linguistically, the complex process of second-language acquisition requires up to two years of instruction for ESL learners to develop basic interpersonal communication skills (BICS) and from five to seven years or longer to reach cognitive academic language proficiency (CALP, Collier, 1989; Cummins, 1994). Many ESL learners experience limited educational success. Latimer (2000) examined the 1996-1999 provincial achievement test scores of students in the CBE and found that ESL learners in grades 3, 6, and 9 were between 16 to 28 percentage points behind other students in language arts. An examination of high school completion rates among students in Alberta found no significant differences in high school completion outcomes between students with no ESL coding and those who were coded as ESL in elementary grades but did not receive ESL coding during subsequent junior and senior high school years (75.6\% vs. $75.4 \%$, Alberta Education, 2009). The same study, however, found that three years after entering grade 10, those who were coded as ESL in junior high grades had a lower high school completion rate $(61.7 \%)$ than those with no ESL coding $(75.6 \%)$. Toohey and Derwing (2008) examined data from the records of ESL students in Vancouver and found that approximately $60 \%$ of the ESL students in the Vancouver School District graduated from high school.

In addition, many ESL learners face cognitive and psychosocial challenges related to cultural adjustment and adaptation (Delgado, Jones, \& Rohani, 2005). Some experience difficulties in forming cross-ethnic friendships, in being overly reliant on support from peers with similar cultural backgrounds, in overcoming feelings of alienation and isolation, and in having limited access to positive role models and mentors (Anisef \& Kil- 
bride, 2003; James, 1997). Studies have shown that many ESL learners struggle to achieve positive identity-formation due to conflict between parental values, including those of the ethnic community, and the values of the greater community and the pervasive effect of internalized racism (Desai \& Subramanian, 2000; Ngo, 2011). A number of ESL learners experience a range of physical and mental health challenges. Those raised in families disadvantaged by socioeconomic status are at higher risk of malnutrition (Weissman, 1994). Some have been exposed to communicable diseases in their home countries (Cookson et al., 1998). ESL learners with a refugee background who were subjected to persecution, war, violence, loss of family members, and trauma in their home countries or during migration are more likely to experience post-traumatic stress syndrome (Derluyn \& Broekaert, 2007). Recent research has linked poor mental health among some visible minorities to their experiences of racism and discrimination (Davis \& Stevenson, 2006; Zayas, 2001).

\section{Theoretical Framing}

This study was guided by the multicultural education approach. Multicultural education, rooted in the perspective of cultural pluralism, recognizes cultural diversity as a salient, positive element in a society (Banks, 1994; Joshee \& Johnson, 2007; Tator \& Henry, 1991). It encourages administrators and staff of the education system to examine critically any existing stereotypes and discriminatory practices in schools and to address educational equity to promote meaningful educational opportunities for culturally diverse student populations (Cenoz \& Genesee, 1998; Parla, 1994). The theoretical framework of cultural competence further informed the development of the survey. Ngo (2008) defines cultural competence in the organizational/institutional context as the personal and collective ability to function effectively in cross-cultural situations. At the individual level, cultural competence involves congruent personal philosophies, attitudes, knowledge, and skills that enable individuals to interact with people of diverse cultural values, beliefs, customs, and practices with respect, appreciation, and effectiveness. At the system level, cultural competence refers to the demonstrated ability of an organization to work effectively with culturally diverse populations through explicit integration of cultural diversity into all aspects of its organizational values, structures, policies, and practices. Thus culturally competent schools should address cultural diversity in the school culture, in representation on school councils and in school personnel, school policy, communication, professional development, resource allocation, research and inquiry, curriculum development, classroom practice, school community relations and collaboration, and support to families (Coelho, 1998; Ngo, 2003). 


\section{Method}

\section{Survey Design}

This study uses a survey research design to gain understanding of the perspectives of self-identified ESL learners and their parents on how Alberta schools respond to cultural diversity. The questionnaire focuses on how schools address cultural diversity in various aspects of organizational structures and functions, including school environment, cultural representation, school practices, school- and student-family interactions and communication, staff competences, school-community collaboration, and involvement of families in school activities. A team of six academic researchers and community leaders served as research advisors and provided their feedback and recommendations throughout the development of the questionnaire. The survey was piloted with a group of ESL learners and a group of parents of ESL learners for further feedback and recommendations. The survey was available in Arabic, Chinese, English, Filipino, German, Hindi, Italian, Polish, Spanish, Urdu, and Vietnamese. The translated versions of the survey were cross-checked by independent reviewers to ensure accuracy of translation.

\section{Participants}

The researchers recruited participants from various ethnocultural communities in Calgary and Edmonton. Although the sample for this study was not randomized, our sampling strategies took into consideration diverse levels of student enrollment in various school boards, immigration patterns, gender representation, and school divisions. Two teams of community research assistants (17 members in Calgary and 19 in Edmonton) tapped into the networks of community-serving agencies, ethnocultural groups, and ethnic media to recruit the research participants. The research teams collected the data during the 2007-2008 school year. A total of 242 self-identified ESL learners and their parents from four major school boards in Alberta, namely, the $\mathrm{CBE}, \mathrm{CCSD}$, EPSB, and ECSD, participated in the study.

The student sample reflected the enrollment patterns of students in the four major school boards. The percentages of student respondents in the survey from the CBE, CCSD, EPSB, and ECSD were 32.6\%, 18.2\%, 30.2\%, and $19.0 \%$ respectively. The total percentages of student respondents in kindergarten, elementary, junior high, and senior high across the four school boards were $1.7 \%, 41.7 \%, 28.5 \%$, and $28.5 \%$ respectively. The sample consisted of equal numbers of male and female students (50\%). Consistent with immigration trends in Canada, respondents were more likely to have arrived from East and Southeast Asia (36.8\%), followed by those from West, Central, and South Asia, the Middle East (19.4\%), and Africa (16.1\%). The Canadian-born ESL student population made up $14.0 \%$ of the sample. A small majority of respondents $(63.1 \%)$ had been in Canada for five or fewer years. 
The parent sample included a disproportionate number of female respondents $(72.3 \%)$. A small majority of the respondents (53.8\%) were in the $40-50$ year-old cohort, followed by those between the ages of 30 and 39 (33.3\%). With respect to marital status, $83.1 \%$ of the respondents were married. The respondents were more likely to have arrived from East and Southeast Asia (44.5\%), followed by those from West, Central, and South Asia, the Middle East (21.0\%), and Africa (20.6\%). A small majority of the parent respondents $(65.3 \%)$ had been in Canada for five years or fewer. About one in two parent respondents $(56.8 \%)$ had received university education in their home countries.

This study provides insights into first-hand experiences of the participant group in Alberta schools; however, it has some limitations. It focused solely on the perceptions of self-identified ESL students and their parents; it recognized that students were not always aware of all aspects of organizational structures and functions; it based the findings on a relatively small and not randomized sample of participants; and it found that numbers of respondents to some questions were less than ideal.

\section{Results}

Cultural competence requires schools to integrate cultural diversity meaningfully into all aspects of its structures and functions. Our results provide insights into the perceptions of ESL students and parents on how schools address cultural diversity in the following areas: school environment, cultural representation, school practices, school- and student-family interactions and communication, staff competences, school-community collaboration, and involvement of families in school activities. In addition, they examine congruence in the perceptions of ESL students and parents with regard to school practices.

\section{School Environment}

Table 1 shows the opinions of student and parent respondents about the physical school environment. One in two parent respondents $(50.4 \%)$ and a slightly higher percentage of student respondents (58.4\%) indicated that they had seen signs of welcome and notices in diverse languages in their schools. Similarly, one in two parent and student respondents $(52.2 \%$ and $51.5 \%$ respectively) reported that they had seen photographs of people of diverse cultures in their schools. However, the respondents disagreed in their views on the availability of books about other cultures. Whereas $66.7 \%$ of the student respondents noticed books about diverse cultures in their schools, only $42 \%$ of the parents observed cultural diversity in book selections. Approximately one in five parent and student respondents (21.9\% and $17.3 \%$ respectively) indicated that their schools had no material that related to the presence of other cultures in their schools.

Parent and student respondents demonstrated modest levels of agreement with the statements related to the school social environment (Table 2). Only 
Table 1

Physical School Environment

\begin{tabular}{lcccc}
\hline & \multicolumn{2}{c}{ Parents } & \multicolumn{2}{c}{ Students } \\
\hline & $N$ & $\%$ & $N$ & $\%$ \\
\hline $\begin{array}{l}\text { Signs of welcome and notices in different } \\
\text { languages }\end{array}$ & 113 & 50.4 & 135 & 58.4 \\
$\begin{array}{l}\text { Photographs of people of diverse cultures } \\
\text { Books about diverse cultures }\end{array}$ & 117 & 52.2 & 119 & 51.5 \\
Nothing that tells me about diverse cultures & 49 & 42.0 & 154 & 66.7 \\
\hline
\end{tabular}

Note. Some columns do not add up to $100 \%$ due to multiple responses.

$25.8 \%$ of parent respondents and $31.4 \%$ of student respondents reported that their schools encouraged students and teachers to use languages other than English. About one in two parents (50.3\%) and students (46.4\%) believed that there were adequate opportunities for intercultural or interracial interactions. Fewer than half the parent and student respondents $(44.7 \%$ and $37.1 \%$ respectively) agreed or strongly agreed with the statement that there were cultural activities throughout the school year. Approximately $41.8 \%$ of parent respondents and $30.7 \%$ of student respondents assessed the celebration of histories and contributions of cultural and racial groups in their schools as adequate.

Table 2

Social School Environment

\begin{tabular}{|c|c|c|c|c|}
\hline \multirow[b]{2}{*}{ Agree/Strongly agree } & \multicolumn{2}{|c|}{ Parents } & \multicolumn{2}{|c|}{ Students } \\
\hline & $N$ & $\%$ & $N$ & $\%$ \\
\hline Use of heritage language encouraged & 42 & 25.8 & 74 & 31.4 \\
\hline $\begin{array}{l}\text { Opportunities for inter-cultural/racial } \\
\text { interaction }\end{array}$ & 97 & 50.3 & 110 & 46.4 \\
\hline Cultural activities throughout school year & 84 & 44.7 & 88 & 37.1 \\
\hline $\begin{array}{l}\text { Celebration of histories and contributions } \\
\text { of cultural and racial groups }\end{array}$ & 71 & 41.8 & 73 & 30.7 \\
\hline
\end{tabular}

Note. Some columns do not add up to $100 \%$ due to multiple responses. 
Table 3

Cultural Representation in Schools

\begin{tabular}{lcccc}
\hline & \multicolumn{2}{c}{ Parents } & \multicolumn{2}{c}{ Students } \\
\hline Agree/Strongly agree & $N$ & $\%$ & $N$ & $\%$ \\
\hline $\begin{array}{l}\text { Cultural diversity among school } \\
\text { council members }\end{array}$ & 131 & 55.5 & 83 & 61.0 \\
$\begin{array}{l}\text { Cultural diversity among school } \\
\text { administration }\end{array}$ & 106 & 44.9 & 62 & 38.8 \\
\begin{tabular}{l} 
Cultural diversity among teachers \\
\hline
\end{tabular} & 82 & 34.5 & 106 & 55.2 \\
\hline
\end{tabular}

Note. Some columns do not add up to $100 \%$ due to multiple responses.

\section{Cultural Representation}

Parent and student respondents were asked to evaluate cultural diversity in their school councils, administration, and teaching staff. As demonstrated in Table 3, a small majority of parent and student respondents $(55.5 \%$ and $61.0 \%$ respectively) agreed or strongly agreed that their school council members reflected cultural diversity in their communities. Fewer than half of the parent and student respondents ( $44.9 \%$ and $38.8 \%$ respectively) felt that there was adequate cultural diversity among school administrators. Parent and student respondents expressed markedly different opinions about cultural diversity among teaching staff. Whereas one in two student respondents $(55.2 \%)$ agreed or strongly agreed with the statement that teaching staff represented diverse cultural groups in their communities, only one in three parent respondents $(34.5 \%)$ supported this statement.

\section{Integration of Cultural Diversity into School Practices}

Table 4 shows the integration of cultural diversity into school practices through inclusion of methods of teaching, topics in curriculum, development of school support services, selection of textbooks, and planning of extracurricular activities. A modest majority of parent respondents felt that schools had taken cultural diversity into consideration through its varied practices. About one in two parent respondents agreed or strongly agreed that schools had included cultural diversity in their methods of teaching $(52.7 \%)$ and selection of textbooks (53.6\%). A slightly higher percentage of parent respondents felt that schools showed cultural diversity in decisions about topics to teach $(57.3 \%)$, development of school support services (60.1\%), and planning of extracurricular activities (61.4\%).

Compared with parent respondents, student respondents were less enthusiastic about their school practices. Approximately four in 10 student re- 
Table 4

Integration of Cultural Diversity into School Practices

\begin{tabular}{llccc}
\hline & \multicolumn{2}{c}{ Parents } & \multicolumn{2}{c}{ Students } \\
\hline Agree/Strongly agree & $N$ & $\%$ & $N$ & $\%$ \\
\hline Choosing different ways of teaching & 69 & 52.7 & 68 & 39.1 \\
Deciding what to teach & 75 & 57.3 & 44 & 27.5 \\
Developing school support services & 92 & 60.1 & 74 & 44.3 \\
Selecting textbooks & 74 & 53.6 & 81 & 43.1 \\
Developing extra-curriculum activities & 94 & 61.4 & 70 & 29.3 \\
\hline
\end{tabular}

Note. Some columns do not add up to $100 \%$ due to multiple responses.

spondents agreed or strongly agreed that their schools had integrated cultural diversity into methods of teaching (39.1\%), development of school support services $(44.3 \%)$, and selection of text books (43.1\%). Another one in three felt that schools had integrated cultural diversity into the teaching curriculum $(27.5 \%)$ and the planning of extracurricular activities (29.3\%). Overall, parents and students demonstrated a divergence of opinion about the integration of cultural diversity into school practices. Their opinions differed markedly with respect to the integration of cultural diversity in the curriculum, development of school support services, and planning of extracurricular activities.

\section{Cultural Competence of School Staff}

With respect to the capacity of school staff to deal with cultural diversity, a small majority of parent and student respondents $(63.5 \%$ and $56.2 \%$ respectively) agreed or strongly agreed with the statement that school staff show

Table 5

Cultural Competence of School Staff

\begin{tabular}{lcccc}
\hline & \multicolumn{2}{c}{ Parents } & \multicolumn{2}{c}{ Students } \\
\hline Agree/Strongly agree & $N$ & $\%$ & $N$ & $\%$ \\
\hline $\begin{array}{l}\text { Show understanding of the immigrant } \\
\text { experience. }\end{array}$ & 115 & 63.5 & 113 & 56.2 \\
$\begin{array}{l}\text { Openly discuss issues related to racism } \\
\text { and discrimination. }\end{array}$ & 65 & 46.8 & 83 & 50.9 \\
\hline
\end{tabular}

Note. Some columns do not add up to $100 \%$ due to multiple responses. 
understanding of the immigrant experience (Table 5). Almost half the parent and student respondents (46.8 and 50.9\% respectively) reported that school personnel openly discussed issues related to racism and discrimination.

\section{Student- and Family-School Interactions}

Respondents provided an overall positive assessment of their interactions with school personnel and students (Table 6). Parent respondents were most likely to report that librarians showed respect for their cultural beliefs and practices $(83.6 \%)$. Student respondents, however, rated their interactions with their teachers more favorably $(83.7 \%)$ than interactions with librarians. On the other hand, parent and student respondents expressed reservations about interactions with other students. Only $60.0 \%$ of parent respondents and $64.1 \%$ of student respondents felt that other students showed respect for their cultural beliefs and practices.

Table 6

Interactions Between Students/Parents and School Personnel and Students

\begin{tabular}{|c|c|c|c|c|}
\hline \multirow[b]{2}{*}{ Agree/Strongly agree } & \multicolumn{2}{|c|}{ Parents } & \multicolumn{2}{|c|}{ Students } \\
\hline & $N$ & $\%$ & $N$ & $\%$ \\
\hline \multicolumn{5}{|l|}{$\begin{array}{l}\text { Positive experience in interactions } \\
\text { with school personnel and students }\end{array}$} \\
\hline Principal or vice-principal & 136 & 78.6 & 126 & 79.7 \\
\hline Counselor & 119 & 79.3 & 106 & 75.2 \\
\hline Teachers & 161 & 77.0 & 174 & 83.7 \\
\hline Receptionist & 142 & 73.6 & 106 & 74.1 \\
\hline Librarian & 112 & 83.6 & 129 & 76.8 \\
\hline School aids/assistants & 102 & 77.9 & 98 & 74.8 \\
\hline Students & 111 & 60.0 & 134 & 64.1 \\
\hline \multicolumn{5}{|l|}{ Teacher-student interaction } \\
\hline $\begin{array}{l}\text { My teachers treat me as equal to } \\
\text { other students }\end{array}$ & - & - & 173 & 80.5 \\
\hline $\begin{array}{l}\text { My teachers have high expectations for } \\
\text { my academic success }\end{array}$ & - & - & 143 & 74.1 \\
\hline $\begin{array}{l}\text { My teachers are supportive of my future } \\
\text { career dream }\end{array}$ & - & - & 135 & 59.5 \\
\hline
\end{tabular}

Note. Some columns do not add up to $100 \%$ due to multiple responses. 
Table 7

School Responses to Cultural Conflicts

\begin{tabular}{lcccc}
\hline \multicolumn{2}{c}{ Parents } & \multicolumn{2}{c}{ Students } \\
\hline & $N$ & $\%$ & $N$ & $\%$ \\
\hline $\begin{array}{l}\text { I have experienced cultural conflicts } \\
\text { with school staff }\end{array}$ & 19 & 9.0 & 18 & 8.2 \\
$\quad$ Yes & 192 & 91.0 & 201 & 91.8 \\
$\quad$ No & & & & \\
School has been fair in dealing with & 10 & 37.0 & 6 & 33.3 \\
cultural conflicts & 8 & 29.6 & 5 & 27.8 \\
$\quad$ Disagree/strongly disagree & 9 & 33.3 & 7 & 38.9 \\
$\quad$ Neutral & & & & \\
$\quad$ Agree/strongly agree & & & & \\
\hline
\end{tabular}

Note. Some columns do not add up to $100 \%$ due to rounding.

Student respondents elaborated on their interactions with teachers. About four in five students $(80.5 \%)$ felt strongly that their teachers treated them as equal to other students. A smaller percentage of (74.1\%) indicated that their teachers had high expectations for their academic success. Overall, a small majority of student respondents (59.5\%) indicated that their teachers were supportive of their dreams of a future career.

When asked if they had experienced conflicts with school staff due to cultural differences (Table 7 ), only $9.0 \%$ of parent respondents and $8.2 \%$ of student respondents reported such conflicts. Among this group, only $33.3 \%$ of parent respondents agreed or strongly agreed with the statement that schools were fair in dealing with cultural conflicts. A slightly higher percentage of student respondents (38.9\%) expressed agreement with this statement.

Table 8

Access of Families to Interpretation and First Language Support

\begin{tabular}{lllll}
\hline & \multicolumn{2}{c}{ Parents } & \multicolumn{2}{c}{ Students } \\
\hline Agree/Strongly agree & $N$ & $\%$ & $N$ & $\%$ \\
\hline Access to interpreters when needed. & 94.0 & 52.5 & 91 & 47.6 \\
$\begin{array}{l}\text { Access to written information in my } \\
\text { first language. }\end{array}$ & 59.0 & 31.6 & 52 & 27.5 \\
\hline
\end{tabular}

Note. Some columns do not add up to $100 \%$ due to multiple responses. 
Table 9

Modes of Communication

\begin{tabular}{lcccc}
\hline & \multicolumn{2}{c}{ Parents } & \multicolumn{2}{c}{ Students } \\
\hline & $N$ & $\%$ & $N$ & $\%$ \\
\hline Parent-teacher interview & 128 & 54.5 & 188 & 80.0 \\
Phone calls & 56 & 24.5 & 101 & 42.6 \\
Home visits & 4 & 1.8 & 9 & 3.8 \\
Requested meetings & 31 & 13.8 & 60 & 25.3 \\
Notes or letters & 84 & 37.8 & 118 & 49.8 \\
\hline
\end{tabular}

Note. Some columns do not add up to $100 \%$ due to multiple responses.

\section{Family-School Communication}

With respect to immigrants' access to language support, about one in two parent respondents and student respondents (52.5\% and $47.6 \%$ respectively) agreed or strongly agreed that they had ready access to interpreters (Table 8). Only $31.6 \%$ of parent respondents and $27.5 \%$ of student respondents affirmed that they had ready access to written information in their first language.

Table 9 elaborates the modes of communication between schools and families. Parent and student respondents identified parent-teacher interviews, notes or letters, and telephone calls as the primary means of communication between their families and schools. However, student respondents consistently reported higher percentages of the use of various modes of communication between their families and schools than did parent respondents.

\section{School-Community Collaboration}

This section of the survey asked parent and student respondents if their schools worked with community groups and agencies to provide services for students and their families of diverse cultural backgrounds. One in five parent respondents $(20.1 \%)$ and student respondents $(16.7 \%)$ reported their awareness of existing school-community partnerships to support culturally diverse families (Table 10). About $30.5 \%$ of parent respondents and $14.6 \%$ of student respondents indicated that their schools did not work with community groups and service providers to support culturally diverse families. A large percentage of parent and student respondents ( $49.4 \%$ and $68.6 \%$ respectively) acknowledged that they did not know whether their schools were working with community groups and agencies to provide such services. Among participants who had used the existing services for culturally diverse families, one in two parent respondents agreed or strongly agreed with the 
Table 10

School-Community Collaboration

\begin{tabular}{lcccc}
\hline & \multicolumn{2}{c}{ Parents } & \multicolumn{2}{c}{ Students } \\
& $N$ & $\%$ & & $\%$ \\
\hline $\begin{array}{l}\text { My school is working with community } \\
\text { groups and agencies to provide services }\end{array}$ & & & & \\
to culturally diverse families & 48 & 20.1 & 40 & 16.7 \\
$\quad$ Yes & 73 & 30.5 & 35 & 14.6 \\
$\quad$ No & 118 & 49.4 & 164 & 68.6 \\
$\quad$ Don't know & & & & \\
Services for culturally diverse students & 5 & 10.4 & 11 & 28.2 \\
and families are effective & 19 & 39.6 & 11 & 28.2 \\
$\quad$ Disagree/ strongly disagree & 24 & 50.0 & 17 & 43.6 \\
$\quad$ Neutral & & & & \\
$\quad$ Agree/ strongly agree & & & & \\
\hline
\end{tabular}

Note. Some columns do not add up to $100 \%$ due to rounding.

statement that services for culturally diverse students and families were effective. A slightly lower percentage of student respondents (43.6\%) agreed with the statement.

\section{Involvement of Families in School Activities}

Parent and student respondents perceived modest efforts on the part of schools to involve them in school activities (Table 11). One in four parent respondents felt strongly that schools involved them in planning processes to promote diverse cultures $(25.9 \%)$ or to help school staff gain cross-cultural skills and knowledge (27.3\%). About one in three parent respondents affirmed that their children's schools involved them in developing services to help culturally diverse students learn $(30.9 \%)$, creating plans to communicate with culturally diverse families (32.5\%), and developing school services to support culturally diverse families dealing with difficult situations (31.3\%). Compared with parent respondents, student respondents rated school efforts to engage culturally diverse families in school activities more positively. One in three $(33.9 \%)$ reported that their schools involved them in planning processes to promote diverse cultures. About $44.2 \%$ also indicated that their schools involved them in the development of school services to help students of diverse cultures learn. Overall, student respondents were more likely than their parent counterparts to agree with the statement that they were happy 
Table 11

Schools' Efforts to Involve Families in School Activities

\begin{tabular}{|c|c|c|c|c|}
\hline \multirow[b]{2}{*}{ Agree/Strongly agree } & \multicolumn{2}{|c|}{ Parents } & \multicolumn{2}{|c|}{ Students } \\
\hline & $N$ & $\%$ & $N$ & $\%$ \\
\hline Develop a plan to promote cultures. & 42 & 25.9 & 76 & 33.9 \\
\hline $\begin{array}{l}\text { Develop school services to help students } \\
\text { of different cultures learn. }\end{array}$ & 46 & 30.9 & 99 & 44.2 \\
\hline $\begin{array}{l}\text { Help school staff gain cross cultural } \\
\text { skills/knowledge. }\end{array}$ & 41 & 27.3 & - & - \\
\hline $\begin{array}{l}\text { Create a plan to communicate with } \\
\text { families of different cultural and } \\
\text { language backgrounds. }\end{array}$ & 50 & 32.5 & - & - \\
\hline $\begin{array}{l}\text { Develop school services to support } \\
\text { culturally diverse families that deal } \\
\text { with difficult situations. }\end{array}$ & 45 & 31.3 & - & - \\
\hline $\begin{array}{l}\text { Overall satisfaction with school } \\
\text { responses to cultural diversity. }\end{array}$ & 70 & 31.5 & 139 & 59.1 \\
\hline
\end{tabular}

Note. Some columns do not add up to $100 \%$ due to multiple responses.

with how schools dealt with cultural diversity. Whereas $59.1 \%$ of student respondents reported a high level of satisfaction with the efforts of their schools, only $31.5 \%$ of parent respondents felt the same way.

\section{Congruence in Parents' and Students' Responses}

Chi-square analysis was conducted to examine the differences in parents' and students' responses to the 41 common items in the eight areas of focus for this study: school environment (physical and social), cultural representation, integration of cultural diversity into school practices, competence of school staff, family, and school interactions (between families and school personnel and students, student-teacher relationships, conflict resolution), family and school communication (language support, modes of communication), school and community collaboration, and involvement of families in school activities. The results reveal significant differences in parents' and students' responses to 21 of the 41 common items of the surveys (Table 12). Notably, chi-square analysis points out significant differences in students' and parents' opinions with respect to the school social environment, modes of familyschool communication, involvement of families in school activities, and overall level of satisfaction with how schools incorporate cultural diversity. Furthermore, test results show significant differences in students' and parents' responses to several indicators related to cultural representation, inte- 
gration of cultural diversity into school practices, interactions between families and school personnel and students, and student-teacher relationships. The results of the chi-square tests, however, found no significant differences in parents' and students' assessments of the physical school environment, cultural competence of school staff, schools' responses to conflict resolution, access to language support, and school-community collaboration.

Table 12

Congruence of Responses from Parents and Students

\begin{tabular}{|c|c|c|c|}
\hline & $\chi^{2}$ & $d f$ & $p$ \\
\hline \multicolumn{4}{|l|}{ School environment } \\
\hline \multicolumn{4}{|l|}{ Physical environment } \\
\hline Multilingual signs & 3.104 & 1 & 0.08 * \\
\hline Multicultural photographs & 0.023 & 1 & 0.88 \\
\hline Multicultural books & 0.00007 & 1 & 0.99 \\
\hline Nothing to celebrate multiculturalism & 1.448 & 1 & 0.23 \\
\hline \multicolumn{4}{|l|}{ Social environment } \\
\hline Use of heritage languages & 10.900 & 4 & $0.03^{\star *}$ \\
\hline Opportunities for intercultural interactions & 7.949 & 4 & 0.09 * \\
\hline Availability of cultural activities & 12.795 & 4 & 0.01 ** \\
\hline Celebration of cultural histories/contributions & 15.162 & 4 & 0.00 ** \\
\hline \multicolumn{4}{|l|}{ Cultural representation } \\
\hline School council & 7.745 & 1 & $0.01^{* *}$ \\
\hline Administration & 1.765 & 1 & 0.18 \\
\hline Teachers & 55.722 & 1 & 0.00 ** \\
\hline \multicolumn{4}{|l|}{ Integration of cultural diversity into school practices } \\
\hline Methods of teaching & 15.868 & 4 & 0.00 ** \\
\hline Curriculum & 30.541 & 4 & 0.00 ** \\
\hline School support services & 11.547 & 4 & $0.02^{* \star}$ \\
\hline Text book selection & 6.995 & 4 & 0.14 \\
\hline Extra curriculum activities & 14.633 & 4 & 0.01 ** \\
\hline \multicolumn{4}{|l|}{ Cultural competence of school staff } \\
\hline Knowledge of immigrant experience & 6.372 & 4 & 0.17 \\
\hline $\begin{array}{l}\text { Knowledge of issues related to racism } \\
\text { and discrimination }\end{array}$ & 7.328 & 4 & 0.12 \\
\hline
\end{tabular}


Congruence of Responses from Parents and Students

\begin{tabular}{lccc}
\hline & $\chi^{2}$ & $d f$ & $p$ \\
\hline Student/ family-school interactions & & & \\
\hline Interaction with school personnel and students & & & \\
$\quad$ Administrators & 14.324 & 4 & $0.01^{\text {** }}$ \\
Counselors & 20.725 & 4 & $0.00^{* *}$ \\
Teachers & 18.360 & 4 & $0.00^{* *}$ \\
Receptionists & 8.185 & 4 & $0.09^{*}$ \\
Librarians & 9.101 & 4 & $0.06^{*}$ \\
School aides/assistants & 5.037 & 4 & 0.28 \\
$\quad$ Students & 4.128 & 4 & 0.39 \\
Student-teacher relationship & & & \\
$\quad$ Equal treatment of students & 9.743 & 4 & $0.04^{\text {** }}$ \\
High expectations for academic success & 2.481 & 4 & 0.65 \\
Conflict resolution & & & \\
$\quad$ Have experienced cultural disagreements & 0.084 & 1 & 0.77 \\
Fairness in dealing with cultural disagreements & 1.864 & 3 & 0.60 \\
\hline
\end{tabular}

Family-school communication

$\begin{array}{llll}\text { Language support } & & & \\ \text { Access to interpreters } & 1.354 & 4 & 0.85 \\ \text { Access to written information in first languages } & 7.214 & 4 & 0.12 \\ \text { Modes of communication } & & & \\ \text { Parent-teacher interview } & 22.086 & 1 & 0.00 \text { ** } \\ \text { Phone calls } & 56.636 & 1 & 0.00^{* *} \\ \text { Home visits } & 14.773 & 1 & 0.00^{* *} \\ \text { Requested meetings } & 38.629 & 1 & 0.00^{* *} \\ \text { Written correspondence } & 54.110 & 1 & 0.00^{* *}\end{array}$

School-community collaboration

\begin{tabular}{llll}
\hline Availability of culturally focused services & 3.494 & 1 & $0.06^{*}$ \\
Quality of services & 7.168 & 4 & 0.13 \\
\hline
\end{tabular}

Involvement of families

\begin{tabular}{llll}
\hline Promoting cultures & 26.712 & 4 & $0.00^{* *}$ \\
Developing services for culturally diverse students & 28.558 & 4 & $0.00^{* *}$ \\
Level of satisfaction & 47.483 & 4 & $0.00^{* *}$ \\
\hline
\end{tabular}

${ }^{* *} p<.05,{ }^{*} p<.1$. 


\section{Discussion}

This study sought to illuminate the perceptions of ESL learners and their parents about schools' responses to cultural diversity in Alberta, particularly with respect to school environment, cultural representation, school practices, cultural competence of school staff, school-student-family interactions, family-school communication, school-community collaboration, and involvement of ethnocultural families in school activities. The results demonstrate that parent and student respondents provided mediocre assessments of school responses to cultural diversity in most areas except interactions with school personnel. Parent and student respondents assessed schools least favorably with respect to encouragement of heritage languages in schools, availability of culturally focused services in schools to support ethnocultural families, and involvement of ethnocultural families in promoting their cultures. Overall, parent and student respondents demonstrated congruence in their answers to 21 of the 41 common items in the parent and student surveys. Their divergent opinions in a number of areas point to the need for more support for families to strengthen communication and understanding of school issues among parents and students.

The results of this study are consistent with the findings discussed in the 2004 review of ESL K-12 program implementation in Alberta (Howard Research \& Management Consulting, Inc., 2006). For example, among 1,072 schools surveyed for the Howard report, only 19\% had a plan or strategy to address cultural diversity and competence, and $29 \%$ had a plan to involve parents of ESL students meaningfully in supporting students' learning. With respect to school-community partnership, $28.5 \%$ of schools had partnerships with ethnocultural groups and immigrant-serving agencies to provide interpretation and translation to families with limited English. The report further highlighted that $65.0 \%$ of schools had never, almost never, or seldom involved parents in promoting cultural competence. It pointed out incongruences between reported commitment of leadership to cultural competence and actual allocation of resources to promote cultural competence. About $74.0 \%$ of schools asserted that their leadership demonstrated commitment to cultural competence, yet $53.0 \%$ of schools reported that they rarely had adequate resources allocated to address and promote cultural competence.

Results from this study and those from the Howard research report illustrate fragmented responses rather than an integrated approach to cultural diversity and competence in the K-12 education system in Alberta. From the developmental perspective (Cross et al., 1989; Ngo, 2008), fragmented responses to cultural diversity and competence may indicate a pre-cultural competence phase where a system takes notice of the changing diversity in the community and tries some ad-hoc, piecemeal strategies to deal with cultural diversity. Ideally, then the system moves away from add-on functions to develop a coherent, coordinated strategy that effectively affirms cultural 
diversity. However, given that multicultural education has been present in public discourse since the early 1970s (Banks, 2004), fragmented responses to cultural diversity and competence in public education are at best noted for lacking in progress and at worst in using add-on functions as a thin veil to cover systemic inertia or persistent resistance of schools to address inequalities that face ethnic minority learners. Verhoeven (2011), for example, made a strong argument that educational systems have disadvantaged ethnic minority learners with multiple inequalities through institutionalized patterns of norms and routines, manifestation of (dominant) national narratives in structural educational patterns, and segregation and institutional discrimination. Similarly, Egbo (2009) drew attention to biased attitudes of educators, Eurocentric and unrepresentative curricula, culturally dominant assessment practices, and unrepresentative administration and staffing in Canadian school jurisdictions.

Critical insights from this study lend support to calls for system-wide efforts to promote multicultural education and integrate cultural diversity and competence in all aspects of the K-12 education system (Cenoz \& Genesee, 1998; Coelho, 1998; Ngo, 2003). An integrated approach to cultural diversity and competence would emphasize integration of content, a process of knowledge-construction, reduction of prejudice, equity pedagogy, and an empowering school culture and social structure (Banks, 1994, 2004). It would require restructuring of professional preparation programs to ensure teachers' understanding of cultural diversity, varied ways of knowing the world, responsive pedagogy, and leadership (Ragoonaden et al., 2009). School administrators would be required to have specialized training and preparation to provide effective leadership in the development and implementation of culturally responsive policies and educational programs (Herrity \& Glasman, 2010). In addition, collaboration between parents and schools would be seen as crucial to the development of mutual respect and trust, greater parental involvement in their children's school activities, shared responsibilities in decision-making, and shared accountability for outcomes (Friend \& Cook, 1996; Riches \& Curdt-Christiansen, 2010; Skutnabb-Kangas \& Garcia, 1995).

\section{Conclusion and Recommendations}

Findings from this study serve as a reminder that the K-12 education system in Alberta has yet to appreciate fully and realize the advantages of diversity. A culturally competent school system would tap into diverse ways of knowing, teaching, learning, and doing and support the enriched development of intellectual, social, and personal growth of all students. It would be in a good position to address the existing educational inequities that have challenged the academic success and well-being of learners on the basis of social class, immigrant status, language ability, ethnicity, and race. It would strengthen 
the ethical grounding of public education and encourage the upholding of legal responsibilities to ensure access to quality education for all learners as enshrined in provincial, national, and international legislation.

In order to achieve cultural competence, the K-12 education system must move beyond the public discourse on cultural diversity based on political correctness and an add-on or ad-hoc approach. Rather, the system should embrace systemic change and integrate cultural diversity into all structures and functions. The following recommended strategies will ensure that the education ministry, school boards, and schools adopt an integrated approach to cultural diversity and competence.

- Conduct system-wide cultural audits with due attention to policies and guidelines, business plans, curriculum, funding allocation, accountability, and professional requirements;

- Develop plans to integrate cultural diversity into all aspects of governance, administration and management, and services;

- Allocate adequate resources to promote cultural diversity and competence;

- Develop reporting and accountability structures to monitor and evaluate the cultural competence of the education ministry, school boards, and schools;

- Set cultural competence as a professional requirement for all school personnel;

- Offer sustainable professional development opportunities for all school personnel to ensure cultural competence;

- Work with universities to ensure the integration of cultural competence into preservice education and educational leadership programs;

- Provide support for ethnocultural families to strengthen parent-childschool communication and school involvement; and

- Involve ethnocultural families and community groups in the development, implementation, and evaluation of initiatives to address and promote cultural diversity.

\section{Acknowledgments}

This research was conducted for the Coalition for Equal Access to Education. We are grateful for the thoughtful guidance from our advisors: Beth Chatten, Francis Boakye, Hetty Roessingh, HsingChi von Bergmann, Jim Gurnett, Kitt Chanthaboune, and Tracey Derwing. We acknowledge the dedicated support of our team of research assistants: Abida Akbar, Aliya Shahzad, Anne Marie Pham, Cristina Tellez, Ela Kostanecki, Fowzia Issee, Helen Negre, Joy Itamah, Leanne Hildebrand, Linh Bui, Maen Amer, Min Zhao, Namsoo Lee, Peter Ugodo, Santuzza Wolff, Shilu Ghimire, Tony Pascuzzo, Tu Nguyen, Ahmad Sabetghadam, Betty Wong, Biviana Velez Perez, Chantal Hitayezu, Elena Golysheva, Eslela Andaya, Firozeh Penhani, Helen Oywak, Killa Maragang, Lubna Sami, Lydia Yip, Mai Nguyen, Mirela Pirvu, Paul Kalsi, Remy Lastiwka, Sabah Tahir, Salwa Kadri, Wilma Benjamin, and Zahro Shurie. 


\section{The Author}

Known as an advocate for immigrant children and youth, Hieu Van Ngo has supported the work of the Coalition for Equal Access to Education to promote quality, equitable education for learners of diverse backgrounds in Alberta schools. He is an assistant professor in the Faculty of Social Work in the University of Calgary.

\section{References}

Alberta Education. (2009). High school completion longitudinal study. Edmonton, AB: Author, Accountability and Reporting Division.

Alberta Education. (2011). ESL enrolment figures. Edmonton, AB: Author, School Finance.

Anisef, P., \& Kilbride, K.M. (Eds.). (2003). Managing two worlds: The experiences and concerns of immigrant youth in Ontario. Toronto, ON: Canadian Scholars' Press.

Banks, J.A. (1994). Multiethnic education: Theory and practice. Needham Heights, MA: Allyn and Bacon.

Banks, J.A. (2004). Multicultural education: Historical development, dimensions, and practices. In J.A. Banks \& C.A.M. Banks (Eds.), Handbook of research on multicultural education (2nd ed., pp. 3-29). San Francisco, CA: Jossey-Bass.

Cenoz, J., \& Genesee, E. (Eds.). (1998). Beyond bilingualism: Multiculturalism and multilingual education. Clevedon, UK: Multilingual Matters.

Coelho, E. (1998). Teaching and learning in multicultural schools: An integrated approach. Clevedon, UK: Multilingual Matters.

Collier, V. (1989). How long? A synthesis of research on academic achievement in a second language. TESOL Quarterly, 23, 509-531.

Cookson, S., Waldman, R., Gushulak, B., MacPherson, D., Burkle, F., Paquet, C., \& Walker, P. (1998). Immigrant and refugee health. Emerging Infectious Diseases, 4, 427-428.

Cross, T., Bazron, B., Dennis, K., \& Isaacs, M. (1989). Towards a culturally competent system of care. Washington, DC: Georgetown University Child Development Center.

Cummins, J. (1994). The acquisition of English as a second language. In K. SpangenbergUrbschat \& R. Pritchard (Eds.), Kids come in all languages: Reading instruction for ESL students (pp. 36-62). Newark, DE: International Reading Association.

Davis, G.Y., \& Stevenson, H.C. (2006). Racial socialization experiences and symptoms of depression among Black youth. Journal of Child and Family Studies, 15, 293-307.

Delgado, M., Jones, K., \& Rohani, M. (2005). Social work practice with refugees and immigrant youth in the United States. Boston, MA: Pearson Education.

Derluyn, I., \& Broekaert, E. (2007). Different perspectives on emotional and behavioural problems in unaccompanied refugee children and adolescents. Ethnicity and Health, 12(2), 141-162.

Desai, S., \& Subramanian, S. (2000). Colour, culture and dual consciousness: Issues identified by South Asian immigrant youth in the Greater Toronto Area. Council of Agencies Serving South Asians (CASSA) and the South Asian Women's Centre (SAWC).

Egbo, B. (2009). Teaching for diversity in Canadian schools. Toronto, ON: Pearson Education.

Friend, M., \& Cook, L. (1996). Interactions: Collaboration skills for school professionals. White Plains, NY: Longman.

Herrity, V.A., \& Glasman, N.S. (2010). Training administrators for culturally and linguistically diverse school populations: Opinions of expert practitioners. Journal of School Leadership, 20(1), 57-76.

Howard Research \& Management Consulting, Inc. (2006). Review of ESL K-12 program implementation in Alberta: Final report. Edmonton, AB: Alberta Education.

James, D. (1997). Coping with a new society: The unique psychosocial problems of immigrant youth. Journal of School Health, 67(3), 98-102. 
Joshee, R., \& Johnson, L. (Eds.). (2007). Multicultural education policies in Canada and the United States. Vancouver, BC: UBC Press.

Latimer, J. (2000). Demographic information: ESL review task force. Calgary, AB: Calgary Board of Education.

Ngo, H.V. (2003). Toward cultural competency: A practical guide to facilitate active participation of culturally diverse families in schools. Calgary, AB: Coalition for Equal Access to Education.

Ngo, H.V. (2008). Cultural competence: A guide for organizational change. Calgary, AB: Department of Canadian Heritage, Western Region.

Ngo, H.V. (2011). The unravelling of identities and belonging: Criminal gang involvement of youth from immigrant families. Unpublished doctoral dissertation, University of Calgary.

Parla, J. (1994). Educating teachers for cultural and linguistic diversity: A model for all teachers. New York State Association for Bilingual Education Journal, 9, 1-6.

Ragoonaden, K., Cherkowski, S., Baptiste, M., \& Despres, B. (2009). Sntrusntm i7 captikwlh: Unravel the story, the Okanagan way. Alberta Journal of Educational Research, 55, 382-396.

Riches, C., \& Curdt-Christiansen, X.L. (2010). A tale of two Montreal communities: Parents' perspectives on their children's language and literacy development in a multicultural context. Canadian Modern Language Review, 66, 525-555.

Skutnabb-Kangas, T., \& Garcia, O. (1995). Multilingualism for all-General principles? In T. Skutnabb-Kangas (Ed.), Multilingualism for all (pp. 221-256). Lisse, Netherlands: Swets \& Zeitlinger.

Statistics Canada. (2008). Canada's ethnocultural mosaic, 2006 census. Ottawa: Ministry of Industry.

Tator, C., \& Henry, F. (1991). Multicultural education: Translating policy into practice. Ottawa: Multiculturalism and Citizenship Canada.

Toohey, K., \& Derwing, T.M. (2008). Hidden losses: How demographics can encourage incorrect assumptions about ESL high school students' success. Alberta Journal of Educational Research, 54, 178-193.

Verhoeven, M. (2011). Multiple embedded inequalities and cultural diversity in educational systems: A theoretical and empirical exploration. European Educational Research Journal, 10, 189-203.

Weissman, A.M. (1994). Preventive health care and screening of Latin American immigrants in the United States. Journal of the American Board of Family Practice, 7, 310-323.

Zayas, L.H. (2001). Incorporating struggles with racism and ethnic identity in therapy with adolescents. Clinical Social Work Journal, 29, 361-373. 